\title{
Relações Intergovernamentais: aportes para pesquisas em Políticas Públicas Educacionais ${ }^{1}$
}

\author{
Nalú Farenzena \\ Calina Jordânia Pergher \\ Cleusa Conceição Terres Schuch \\ Rosa Maria Pinheiro Mosna
}

Resumo: O texto trata da complementação da União ao Fundeb, do Plano de Ações Articuladas, do Programa Nacional de Apoio ao Transporte do Escolar e do Programa Mais Educação como políticas públicas que envolvem relações intergovernamentais. O objetivo é evidenciar elementos de caráter mais básico da reconstrução de políticas, por meio da caracterização e do contraste entre as quatro ações governamentais, considerando suas delimitações normativas, estudadas por meio de análise documental, com destaque para objetivos, atores e aspectos organizacionais das relações entre entes federativos.

PALAVRAS-CHAVE: políticas públicas de educação; análise de políticas educacionais; relações intergovernamentais na educação.

\section{Intergovernmental Relations: contribution to Educational Public Policies research}

ABSTRACT: The study addresses the complementation of the Brazilian Union towards four public education policies that involve intergovernmental relations: Fundeb, Plano de Ações Articuladas, Programa Nacional de Apoio ao Transporte do Escolar and Programa Mais Educação. The goal is to outline primary elements of policy reconstruction, considering the normative boundaries of the four listed policies. The method is a documental analysis, in which we distinguish the goals, actors and organizational aspects of the relations between the federal entities involved in the analyzed policies.

KEYWORDS: education public policies; educational policies analysis; intergovernmental relations on education.

\footnotetext{
${ }^{1}$ Este texto é uma versão atualizada e revisada de trabalho apresentado no VI Encontro Internacional de Investigadores de Políticas Educativas, realizado na Universidade Federal de Santa Maria, em setembro de 2014 (FARENZENA et al, 2014).
} 


\section{Introdução}

As responsabilidades pela educação pública brasileira são compartilhadas pelos níveis governamentais - União, estados, Distrito Federal e municípios -, observando as respectivas prioridades e competências. Na educação básica, essas responsabilidades envolvem campos próprios de cada governo, assim como colaboração e cooperação. A oferta de educação básica pública é realizada, na sua quase totalidade, pelos governos subnacionais, mas há interveniência da União em dimensões como o financiamento, o planejamento, a regulamentação e a avaliação externa de rendimento escolar.

Na cooperação intergovernamental na educação básica, a União tem o dever de assistir técnica e financeiramente aos estados e aos municípios, para cumprir suas funções redistributiva e supletiva, visando a equidade e o padrão mínimo de qualidade educacional, conforme estabelece o art. 211 da Constituição da República.

Com isso, há programas e ações federais com capilaridade nas redes públicas estaduais e municipais do país que contemplam arranjos intergovernamentais; são propostos ou têm diretrizes gerais estabelecidas sob protagonismo do governo da União, mas se concretizam com o trabalho das administrações públicas estaduais e municipais e das escolas públicas.

Este texto trata de quatro políticas intergovernamentais: a complementação da União ao Fundo de Manutenção e Desenvolvimento da Educação Básica e de Valorização dos Profissionais da Educação (Fundeb), o Plano de Ações Articuladas (PAR), a política de transporte escolar a partir do olhar sobre um de seus programas, o Programa Nacional de Apoio ao Transporte do Escolar (Pnate), e o Programa Mais Educação. Olham-se responsabilidades governamentais para pontuar semelhanças e diferenças nas relações intergovernamentais previstas nas políticas estudadas.

Reunimos aqui resultados de estudos das autoras que focaram políticas federais intergovernamentais na educação básica, estudos estes que articularam diferentes abordagens, métodos e procedimentos, mas que têm em comum a concepção de política pública, a perspectiva de operar com ferramentas da análise de políticas públicas e, de distintos modos, a noção de relações intergovernamentais. $\mathrm{O}$ texto, portanto, por meio da caracterização e do contraste entre as políticas, tem o objetivo principal de evidenciar elementos de caráter mais básico da reconstrução de políticas em estudos de análise de políticas públicas.

Embora os estudos realizados tenham se valido de diversas metodologias e procedimentos, para este artigo trabalhamos com a análise documental de cada política, com maior acento em indícios de (co)responsabilidades governamentais inscritas nos documentos normativos das políticas.

Além desta introdução, há três seções: a primeira com descrição resumida de cada política, a seguinte com um esboço de comparação e a última com a explicitação de âmbitos considerados no constructo analítico das policies em questão.

Antes do próximo segmento, porém, cabe pontuar aqui as noções de políticas públicas e de relações intergovernamentais que utilizamos. 
As políticas públicas podem ser consideradas programas de ação pública, isto é "[...] dispositivos político-administrativos coordenados em princípio em torno de objetivos explícitos" (MULLER; SUREL, 2002, p. 11). Como dispositivos político-administrativos, exigem mobilização para decisões e ações, e por isso têm uma dimensão de concretude, de tradução de prescrições em atos para manter ou alterar uma situação. As políticas públicas podem ser vistas como processos através dos quais são elaboradas as representações que uma sociedade constrói para compreender e agir sobre o real, tal qual ele é percebido (MULLER, 2006). Deste modo, as policies, compreendidas como espaços de construção de sentido, não podem ser reduzidas a um conjunto de estratégias organizacionais, pois são um elemento da participação política, junto a modos tradicionais dessa participação, como o voto ou a militância política.

Muller e Surel (2002) agrupam três elementos que permitem identificar a existência de uma política pública, isto é, elementos que fundam a existência de uma política pública e possibilitam distinguir um complexo de decisões/ações de decisões e ações mais isoladas. Estes elementos podem ser úteis aos pesquisadores na tarefa de reconstrução de políticas ao longo dos estudos, em que sublinhamos a adequação a processos iniciais de sistematização, com base em análise de documentos, relativa ao mapeamento de objetivos e atores, bem como ao sistema de recursos, atribuições e relações constituídos em cada política pública.

O fato da política pública construir um quadro normativo de ação ou um quadro geral de ação é o primeiro recorte apontado pelos autores acima citados. As decisões e ações estão reunidas num quadro geral de ação que funciona como uma estrutura de sentido, um quadro de ação que congrega e mobiliza recursos (em sentido amplo) e produtos para atingir objetivos, finalidades; o significado do termo normativo, neste caso, diz respeito a haver fins a atingir, a um dever ser resultante das decisões/ações que constituem a política. Segundo os autores, os objetivos podem ser implícitos ou explícitos e constitui tarefa dos pesquisadores a sua identificação e reconstrução. Outra observação é a de que o sentido de uma política não é necessariamente unívoco; ao contrário, a política é, muito comumente, incoerente, contraditória, demandando, portanto, dos pesquisadores, a tarefa de reconstruir as lógicas de sentido e de ação no seu processo de elaboração e de implementação.

Outro elemento é que a política pública é expressão do poder público. As decisões e ações revestem-se da autoridade do Estado. A dimensão coercitiva é, pois, presente, pelo menos de modo latente, junto à legitimidade dada pela expertise; os autores assinalam que a dimensão da coerção nem sempre é dominante, sendo muitas vezes apenas potencial, e com grau de influência dependente do tipo de política. Outra advertência dos autores é que a especificidade da ação do Estado não significa reificar o poder público num bloco homogêneo e autônomo, é preciso atentar, na análise de políticas públicas, às interações para expressão do poder público, incluindo as relações entre os agentes governamentais e entre os espaços público e privado. 
Um terceiro recorte é considerar que a política pública constitui uma ordem local, ou seja, um sistema dentro do qual os atores mobilizam recursos e estratégias de poder para realizar objetivos. No espaço dessa ordem local (um âmbito político relativamente autônomo) opera-se a regulação dos conflitos entre os interessados, como também a articulação do público de uma política - indivíduos, grupos ou organizações cuja situação é afetada pela política pública. Os autores observam que os públicos da política não se encontram numa mesma situação de participação ou de possibilidade para influenciar as decisões e ações, por conseguinte, um dos desafios da análise da ação do Estado é construir os modos de ação dos grupos sociais no quadro das políticas públicas e os fatores que influenciam diferentes capacidades de intervenção dos atores na ação pública.

Quanto a relações intergovernamentais, segundo Souza (2006), essa noção diz respeito às conexões entre diferentes níveis de governo. Seu estudo requer examinar os arranjos administrativos e legais que regem essas relações e, igualmente, levar em conta a compreensão de como os conflitos são negociados, ou seja, a negociação política entre os grupos, com ênfase para os atores situados nas diferentes esferas de governo previstas no federalismo brasileiro. $\mathrm{O}$ ordenamento constitucional-legal é uma referência, como também o são os conteúdos das políticas e as sistemáticas que se estabelecem na implementação das políticas intergovernamentais. Neste texto, serão acentuados arranjos administrativos e legais que estão na base das relações intergovernamentais nas quatro políticas que são objeto de atenção.

Tendo em conta os subsídios explicitados nos parágrafos anteriores, referentes a noções da análise de políticas e de relações intergovernamentais, apresentamos a seguir, de modo resumido e considerando pontos em comum, as políticas em questão.

\section{Descrição das políticas}

A complementação da União ao Fundeb, o Pnate, o Programa Mais Educação e o Plano de Ações Articuladas são caracterizados nos seguintes aspectos: objetivo(s); operacionalização (em linhas gerais); tipo de assistência da União previsto; função da União no âmbito de cada programa; critério(s) de priorização; questões controversas; ações dos entes subnacionais no financiamento; instâncias de negociação/diálogo intergovernamental.

\section{Complementação da União ao Fundelb ${ }^{2}$}

O Fundeb passou a vigorar em 2007, em substituição ao Fundo de Manutenção e Desenvolvimento do Ensino Fundamental e de Valorização do Magistério (Fundef). Seus objetivos explícitos são: manter e desenvolver a educação básica e valorizar os profissionais docentes da educação. De modo implícito, objetiva também equiparar a capacidade de financiamento da educação básica dos entes federativos.

É um fundo contábil e redistributivo, composto por uma parte dos recursos da receita resultante de impostos dos estados e dos municípios vinculada à manutenção e ao

${ }^{2}$ Este baseia-se em extensa pesquisa sobre o Fundeb, parte de seus resultados foram publicados em Farenzena (2015). 
desenvolvimento do ensino (MDE) e por recursos complementares da União. Essa complementação é a transferência de recursos a fundos estaduais cujos recursos próprios do governo estadual e das prefeituras não permitem atingir o valor mínimo nacional por aluno.

O valor da complementação da União ao Fundeb deve corresponder a, no mínimo, $10 \%$ dos recursos de contribuição dos governos subnacionais. Em valores constantes, os recursos complementares foram os seguintes: 3,05 bilhões em 2007; 4,30 bilhões em 2008; 6,98 bilhões em 2009; 9,92 bilhões em 2010; 10,70 bilhões em 2011; 10,78 bilhões em 2012; 11,29 bilhões em 2013; 11,55 bilhões em 2014. Em 2007 e 2008, eram oito estados que recebiam complementação: Alagoas, Bahia, Ceará, Maranhão, Pará, Paraíba, Pernambuco e Piauí; Amazonas e Rio Grande do Norte também passaram a receber esse recurso a partir de 2009 e 2010, respectivamente.

A complementação da União ao Fundeb propicia aos estados beneficiados uma elevação apreciável na sua disponibilidade de recursos financeiros para a educação básica. $\mathrm{Na}$ implementação da política, ocorreu um movimento crescente de aproximação na capacidade de financiamento da educação entre os estados brasileiros, isso se considerados exclusivamente os recursos do Fundeb. Essa aproximação se deve ao aumento nos recursos de complementação da União.

Como toda policy, o Fundeb tem suas questões controversas e disputadas. Há, portanto, uma agenda de deliberação sobre o Fundeb, da qual podem ser destacados os seguintes pontos: a contagem de matrículas da rede particular de ensino e uso dos recursos nessa rede; a definição das ponderações entre etapas, segmentos, modalidades e situações de oferta; a aplicação dos $10 \%$ da complementação da União em programas e ações de qualificação da educação, ao que se liga o pagamento do piso salarial profissional nacional do magistério das redes estaduais e municipais de ensino. As deliberações acerca dos dois últimos pontos são de responsabilidade da Comissão Intergovernamental de Financiamento para a Educação Básica de Qualidade, formada por representantes do Ministério da Educação (MEC), do Conselho Nacional de Secretários de Estado da Educação (Consed) e da União Nacional dos Dirigentes Municipais de Educação (Undime).

Mesmo com os avanços obtidos com a implantação do Fundeb, o estabelecimento de novos parâmetros para a formação desse fundo - ou para o financiamento da educação em geral, bem como para a (re)distribuição dos recursos - continua na agenda de deliberação da política educacional do país. Neste cenário, têm sido propostas modificações na política de financiamento em geral, e do Fundeb em particular, com ênfase para a adoção do custo aluno qualidade inicial e do custo aluno qualidade como parâmetros para a definição de recursos financeiros a serem aportados ao fundo redistributivo.

\section{Programa Nacional de Apoio ao Transporte do Escolar (Pnate) ${ }^{3}$}

O Pnate foi instituído pela lei $\mathrm{n}^{\mathrm{o}} 10.880 / 2004$. Seu objetivo inicial era garantir a oferta do transporte escolar aos alunos do ensino fundamental público residentes em 
área rural. Em 2009, o Pnate, assim como outros programas suplementares, passou a abranger a educação básica, antecipando-se, ou já prevendo, a aprovação da Emenda Constitucional $\mathrm{n}^{\circ} 59 / 2009$, que ampliou a faixa etária de obrigatoriedade escolar, que passou a incidir na população dos quatro aos 17 anos de idade. Os recursos repassados aos estados, ao Distrito Federal e aos municípios permitem realizar parcialmente a prestação dos serviços do transporte escolar, seja por meio de despesas com a frota pública ou através da contratação de serviços terceirizados. No entanto, esses recursos têm se apresentado como insuficientes e acabam por ser acrescidos de recursos do salário-educação, da receita de impostos vinculada à MDE e outros de estados e municípios.

O recurso do Pnate é repassado diretamente aos governos pelo Fundo Nacional de Desenvolvimento da Educação (FNDE), sem necessidade de convênio, com base na matrícula apurada no censo escolar do ano anterior; são repassadas nove parcelas anuais, de março a novembro. São os municípios os principais responsáveis pela oferta do transporte escolar: são eles que executam o serviço, mesmo para os alunos das escolas estaduais. Para recebimento dos recursos do Pnate, os municípios podem atender alunos das redes estaduais e, se acordado entre os entes, o FNDE pode repassar os recursos que cabem ao estado diretamente às prefeituras. $O$ controle social do uso do recurso deve ser feito pelo Conselho do Fundeb de cada município, que analisa a prestação de contas no início de cada ano, emite parecer e a encaminha ao FNDE.

$\mathrm{O}$ valor do repasse é estabelecido de acordo com o que preceitua a Resolução $\mathrm{CD} /$ FNDE ${ }^{\circ} 12$, de 17 de março de 2011, com base no Fator de Necessidade de Recursos do Município (FNR-M); este considera a área rural do município, a população que mora no campo, a posição do município na linha de pobreza e o Índice de Desenvolvimento da Educação Básica (Ideb). Esses critérios foram sendo modificados ao longo do programa - um exemplo é o Ideb, acrescido como critério em 2008. A Resolução CD/FNDE no 14 , de 8 de abril de 2009, foi o divisor de águas na definição dos novos e atuais critérios, acima citados; a Resolução CD/FNDE n ${ }^{\circ}$ 12/2011 não modificou os critérios de distribuição dos recursos. Quando o programa foi criado, em 2004, a Resolução CD/FNDE $n^{\circ} 18 / 2004$ estabelecia como critério o número de alunos que residiam na área rural e utilizavam o transporte, e nada mais.

O valor do per capita aluno/ano praticado no Pnate tem sido o seguinte: nos anos de 2006 a 2008, variou entre $R \$ 81,56$ e $\mathrm{R} \$ 116,36$; em 2009, houve reajuste de $8 \%$ e passou a variar de $\mathrm{R} \$ 88,13$ a $\mathrm{R} \$ 125,72$; em 2010 , reajuste de $37 \%$, ficando a variação entre $R \$ 120,73$ e $R \$ 172,24$; entretanto este valor tem se mantido congelado, sendo o mesmo valor no período 2011-2015.

Pontuando questões controversas do Pnate, cabe ponderar que um programa que atendeu em 2014 4,5 milhões de alunos de 5.296 municípios acaba por apresentar políticas de universalização que não dão conta de considerar as diversidades regionais, culturais e sociais. 
Dentre as críticas endereçadas ao Pnate, destacam-se as relativas aos critérios adotados para a distribuição dos recursos entre os entes executores, se estes critérios garantem ou não uma adequada ou justa distribuição dos recursos. Outro ponto que gera descontentamento diz respeito ao valor per capita aluno/ano praticado no Pnate. Comprovadamente, o repasse feito não tem garantido na totalidade o valor gasto pelo ente que efetivamente oferta o transporte escolar (em grande parte as prefeituras), o que torna latente a necessidade de mais recursos da assistência financeira da União para efetivar um valor por aluno que seja menos inexpressivo em relação aos custos do transporte escolar cobertos com recursos dos municípios.

Aos municípios tem cabido a responsabilidade pela oferta e por grande parte do financiamento do transporte escolar, contudo, percebe-se que há um esforço por parte da União na tentativa de ampliar o acesso ao programa (abrangência para a educação básica) e de auxiliar os municípios na oferta desse serviço a partir da criação, no ano de 2007, de outro programa, o Caminho da Escola, pelo qual a União objetiva a definição de padrões de qualidade na oferta do transporte escolar rural.

\section{Plano de ações articuladas (PAR) ${ }^{4}$}

O PAR é um conjunto de processos, apoiado técnica ou financeiramente pelo Ministério da Educação (MEC), que visa ao cumprimento das metas do Plano de Metas Compromisso Todos Pela Educação e à observância das suas diretrizes. O processo de elaboração do PAR está disciplinado na Resolução CD/FNDE nº 29, de julho de 2007. Essa política estabelece ações e subações que deverão ser executadas, algumas exclusivamente pelos municípios e outras em colaboração com a União, para que a educação atinja o índice de desenvolvimento da educação básica (Ideb) de 6 pontos até 2022. Na sua regulamentação, fica claro o objetivo de estabelecer critérios, parâmetros e procedimentos para a transferência e a gestão dos recursos federais de assistência voluntária às redes públicas de educação básica, cuja pactuação entre os entes federados é condição indispensável para a efetivação dessa nova relação, exigindo uma ação conjunta, de colaboração.

Na direção de avanços da política, foi editada a lei ${ }^{\circ} 12.695 / 2012$, a qual preceitua que a União, por meio do MEC, está autorizada a transferir recursos aos estados, aos municípios e ao Distrito Federal, com a finalidade de prestar apoio financeiro à execução das ações do PAR, sem a necessidade de firmar convênio, ajuste, acordo ou contrato. Portanto, o FNDE, órgão do MEC que executa transferências de recursos financeiros, passou a utilizar apenas um termo de compromisso para executar a transferência direta para a implementação das ações pactuadas no PAR.

O PAR não tem como objetivo central a gestão democrática dos sistemas municipais de ensino, contudo, a orientação para a criação dos comitês de acompanhamento da política, constituídos de uma pluralidade de sujeitos, traz no seu bojo o princípio da participação, bem como o incentivo à criação de instâncias colegiadas deliberativas, consultivas e de

${ }^{4}$ Este item baseia-se na tese de doutorado de Schuch (2014). 
controle social (conselho municipal, conselhos escolares, conselho da alimentação escolar), as quais poderão favorecer uma gestão mais democrática da educação. Assim como o PAR apresenta ações/subações de cunho democrático, também disponibiliza outras com perspectiva mais gerencialista, como o Programa PDE Escola, que destina recursos aos estabelecimentos de baixo Ideb, mediante a elaboração de um planejamento estratégico por uma comissão, sem a representação de todos os segmentos da comunidade escolar.

O PAR foi aperfeiçoado ao longo dos anos desde sua implementação, no sentido de atender novas demandas dos governos, dos educadores, da sociedade e dos políticos, corrigir lacunas e estabelecer critérios de atendimento mais transparentes baseados em certos parâmetros mais publicizados, mantendo-se a indução à adoção do planejamento na gestão pelas redes municipais e estaduais de ensino. Cabe acrescentar que a lei $\mathrm{n}^{\mathrm{o}}$ 12.695/2012 previu a instituição de comitê estratégico do PAR no âmbito do MEC, com representação do Consed e da Undime, cujas atribuições são as de definir, monitorar e revisar ações, programas e atividades de assistência técnica ou financeira da União. Com isso, fica reconhecida a coparticipação do MEC e de entidades representativas de gestores estaduais e municipais na educação em deliberações significativas da política.

O PAR, além de ser um dos instrumentos de ação do Plano de Metas, insere-se na função supletiva e redistributiva da União, ou seja, por intermédio do PAR, a União complementa recursos procurando estimular a colaboração entre os entes federados, em conjunto com a sociedade; os recursos financeiros disponibilizados, contudo, ainda são tímidos se consideradas as desigualdades educacionais existentes entre as redes municipais e estaduais, reflexos de uma sociedade profundamente desigual.

\section{Programa Mais Educação (PME)}

O PME foi instituído por meio da portaria normativa interministerial nº 17/2007, como parte do Plano de Desenvolvimento da Educação e estratégia para induzir a ampliação da jornada escolar, prevista no parágrafo $2^{\circ}$ do art. 34 da lei de diretrizes e bases da educação nacional (LDB, lei $\mathrm{n}^{\circ} 9.394 / 960$ ), mediante a oferta de atividades complementares no contra turno. Articula projetos e programas de seis ministérios: Educação, Cultura, Esporte, Ciência e Tecnologia, Desenvolvimento Social e Combate à Fome e Meio Ambiente.

O Programa teve início em 2008, nas capitais e cidades das regiões metropolitanas com mais de 200 mil habitantes; em escolas públicas com Ideb abaixo de 2.9. Os beneficiários prioritários do Programa são estudantes em situação de vulnerabilidade social, de séries com altos índices de evasão, repetência ou defasagem série/idade e beneficiários do Programa Bolsa Família (PBF).

A implementação do Programa ocorre por meio do apoio à realização de oficinas de educação, artes, cultura, esporte e lazer, em escolas e em espaços comunitários e da cidade, de modo a possibilitar, no mínimo, uma jornada escolar de sete horas diárias,

${ }^{5}$ Este item baseia-se na tese de doutorado de Mosna (2014). 
nos cinco dias da semana. Para a realização dessas oficinas são repassados às escolas recursos financeiros, por meio do Programa Dinheiro Direto na Escola (PDDE). O PME prevê, também, o oferecimento de três refeições diárias aos beneficiários, com repasses de recursos ampliados. A principal contrapartida dos governos subnacionais é a disponibilização de um coordenador em cada escola.

As atividades inserem-se em dez macrocampos e são desenvolvidas por profissionais da educação, educadores populares, estudantes e agentes culturais (monitores), em forma de trabalho voluntário, para o qual recebem uma ajuda de custo. Porém, o trabalho voluntário acarreta uma rotatividade de educadores, trazendo problemas para a regularidade das oficinas.

Em 2010, o decreto $\mathrm{n}^{\mathrm{o}} 7.083$ estabeleceu uma inflexão conceitual no Programa, cuja finalidade passou a ser contribuir para a melhoria do desempenho escolar mediante a oferta de educação em tempo integral, na perspectiva da educação integral. Ou seja, de atividades complementares no turno inverso, passou a ser um Programa que propõe uma ressignificação curricular com vistas à educação integral. Em consonância, os objetivos do PME passaram a ser os seguintes: formular a política nacional de educação básica em tempo integral; promover diálogo entre os conteúdos escolares e os saberes locais; favorecer a convivência entre professores, estudantes e suas comunidades; convergir políticas setoriais para o desenvolvimento do projeto político-pedagógico (PPP) de educação integral.

O lançamento dos cadernos da Série Mais Educação, em 2009, contribuiu para o Programa explicitar uma concepção de currículo integrado, constituindo-se num hibridismo autodeclarado entre as ideias de Anísio Teixeira e do Movimento das Cidades Educadoras, bem como fomentar as escolas a promoverem uma mudança curricular.

O PME tem como instâncias de gestão o Fórum Interministerial Mais Educação, em nível federal; os comitês metropolitanos e/ou regionais, com representantes de escolas, secretarias de educação e comunidade para a construção e acompanhamento de planos de ação; os comitês locais, nas escolas, com a mesma finalidade.

Desde sua instituição, em 2007, o Programa apresenta uma ampliação considerável em termos de área de abrangência, de escolas e de estudantes atendidos e inovações. Em 2012, passou a beneficiar as escolas do campo e quilombolas. Esses elementos têm oportunizado o enraizamento social do Programa. No entanto, a se manter esse cenário de expansão e a concepção de educação integral do Programa, a utilização do trabalho voluntário e dos espaços comunitários para a realização regular das atividades precisarão ser repensados, pois poderão comprometer a credibilidade do PME.

\section{Um esboço de comparação}

Elaboramos um quadro-síntese, com algumas categorias descritivas que visam dar melhor visibilidade a cada política/programa, bem como nos possibilitam comparações, das quais pontuamos algumas na sequência. 
Relações Intergovernamentais: aportes para pesquisas em Políticas Públicas Educacionais

Nalú Farenzena, Calina Jordânia Pergher, Cleusa Conceição Terres Schuch e Rosa Maria Pinheiro Mosna

Quadro 1 - Algumas características da complementação da União ao Fundeb, do Pnate, do PAR e do Mais Educação

\begin{tabular}{|c|c|c|c|c|c|c|}
\hline $\begin{array}{l}\text { Categoria } \\
\text { Política }\end{array}$ & Objetivo(s) & $\begin{array}{l}\text { Tipo de } \\
\text { Assistência } \\
\text { da União }\end{array}$ & $\begin{array}{l}\text { Função da } \\
\text { União }\end{array}$ & Critério(s) de priorização & $\begin{array}{l}\text { Ações dos entes } \\
\text { subnacionais no } \\
\text { financiamento }\end{array}$ & $\begin{array}{c}\text { Instância de } \\
\text { negociação } \\
\text { intergovernamental }\end{array}$ \\
\hline $\begin{array}{l}\text { Complementação } \\
\text { da União ao } \\
\text { Fundeb }\end{array}$ & $\begin{array}{l}\text { Manter e desenvolver a educação } \\
\text { básica; valorizar o magistério; equiparar } \\
\text { capacidades de financiamento da } \\
\text { educação dos entes federativos }\end{array}$ & Financeira & $\begin{array}{l}\text { Supletiva e } \\
\text { Redistributiva }\end{array}$ & $\begin{array}{l}\text { Estados cujos recursos } \\
\text { próprios não atingem o valor } \\
\text { mínimo nacional por aluno }\end{array}$ & $\begin{array}{l}\text { Aporte de } \\
\text { recursos aos } \\
\text { fundos estaduais }\end{array}$ & $\begin{array}{l}\text { Comissão } \\
\text { Intergovernamental } \\
\text { de Financiamento } \\
\text { para a Educação } \\
\text { Básica de Qualidade }\end{array}$ \\
\hline Pnate & $\begin{array}{l}\text { Garantir acesso e permanência na escola } \\
\text { aos alunos residentes no meio rural }\end{array}$ & Financeira & $\begin{array}{l}\text { Supletiva e } \\
\text { Redistributiva }\end{array}$ & $\begin{array}{l}\text { Rateio de recursos pelo } \\
\text { Fator de Necessidade de } \\
\text { Recursos do Município, que } \\
\text { contempla: a área rural, a } \\
\text { população que mora no campo, } \\
\text { a posição do município na } \\
\text { linha de pobreza e o Ideb }\end{array}$ & $\begin{array}{c}\text { Aporte de } \\
\text { recursos para } \\
\text { além das } \\
\text { transferências } \\
\text { automáticas de } \\
\text { recursos da União }\end{array}$ & - \\
\hline PAR & $\begin{array}{l}\text { Estabelecer critérios, parâmetros e } \\
\text { procedimentos para a transferência } \\
\text { e a gestão dos recursos federais } \\
\text { de assistência voluntária às redes } \\
\text { públicas de educação básica }\end{array}$ & $\begin{array}{l}\text { Técnico- } \\
\text { Financeira }\end{array}$ & $\begin{array}{l}\text { Supletiva e } \\
\text { Redistributiva }\end{array}$ & $\begin{array}{l}\text { Indicadores de desempenho, } \\
\text { como o Ideb, e a capacidade } \\
\text { financeira e técnica } \\
\text { do ente apoiado }\end{array}$ & $\begin{array}{c}\text { Aporte de } \\
\text { recursos para } \\
\text { além das } \\
\text { transferências } \\
\text { voluntárias de } \\
\text { recursos da União }\end{array}$ & $\begin{array}{l}\text { Comitê Estratégico } \\
\text { do PAR: } \\
\text { deliberações sobre a } \\
\text { assistência da União } \\
\left.\text { (lei n }{ }^{\circ} 12.965 / 12\right)\end{array}$ \\
\hline Mais Educação & $\begin{array}{l}\text { Formular a política nacional } \\
\text { de educação básica em tempo } \\
\text { integral; promover diálogo entre os } \\
\text { conteúdos escolares e os saberes } \\
\text { locais; favorecer a convivência } \\
\text { entre professores, estudantes e suas } \\
\text { comunidades; convergir políticas } \\
\text { setoriais para o desenvolvimento } \\
\text { do PPP de educação integral }\end{array}$ & $\begin{array}{l}\text { Técnico- } \\
\text { Financeira }\end{array}$ & $\begin{array}{c}\text { Supletiva e } \\
\text { Redistributiva }\end{array}$ & $\begin{array}{l}\text { Estudantes em situação de } \\
\text { vulnerabilidade social; de séries } \\
\text { com altos índices de evasão, } \\
\text { repetência e/ou defasagem série/ } \\
\text { idade; e beneficiários do PBF }\end{array}$ & $\begin{array}{l}\text { Aporte de } \\
\text { recursos às } \\
\text { escolas }\end{array}$ & $\begin{array}{l}\text { Fórum } \\
\text { Interministerial } \\
\text { Mais Educação; } \\
\text { comitês } \\
\text { metropolitanos } \\
\text { e/ou regionais; } \\
\text { comitês locais }\end{array}$ \\
\hline
\end{tabular}

Olh@ares, Guarulhos, v. 3, n.2, p. 65-79, nov. 2015 
As quatro políticas em foco convergem no sentido de alocação de recursos financeiros para os entes federativos para promover a melhoria da qualidade da educação básica pública; buscar uma relação de cooperação entre os níveis de governo (inclusive com a criação de instâncias formais de deliberação ou debate); priorizar governos ou escolas em situação mais desfavorável (critério de equidade na ação da União, presente em todas as políticas aqui estudadas).

O instrumento assistência financeira da União integra as políticas e, em duas delas, há também assistência técnica, a qual se realiza, por exemplo, por meio da disponibilização de tecnologias de planejamento e monitoramento de políticas (o PAR) ou de orientações pedagógicas (o Mais Educação).

São políticas que incidem em diferentes vetores da ação do Estado na educação: o Mais Educação tem como foco mais direto o currículo escolar e, por meio de sua qualificação, busca incidir na garantia de padrão de qualidade do ensino; o PAR, na sua concepção mais geral de planejamento e monitoramento de ações pactuadas, mira o aperfeiçoamento da gestão educacional no âmbito estadual/local, ou seja, a gestão democrática da educação; o Pnate atua na garantia de condições para o acesso e a permanência na escola dos alunos do campo; a complementação da União ao Fundeb incide na disponibilização de meios para que os entes mais desprovidos de recursos tenham melhores condições de atuar na educação básica.

No quadro geral de ação ou ordem local de cada política, fica evidente o caráter de complementaridade de ações para a garantia de acesso, permanência e/ou melhores condições de qualidade na educação. As competências da União e dos entes governamentais subnacionais são estabelecidas em normativas nacionais - Constituição e/ou leis e/ou normas do Executivo Federal - e, nessas definições, envolve-se o Poder Legislativo (em função das normas constitucionais e/ou legais da complementação da União ao Fundeb, Pnate e PAR), como também instâncias de diálogo ou de negociação intergovernamental mais ou menos institucionalizadas (complementação da União ao Fundeb, PAR, Mais Educação).

Pelo ponto de vista normativo ou das práticas instaladas, as políticas estudadas são formas de concretização dos princípios de cooperação e colaboração intergovernamental na educação, mesmo com críticas que possam advir de suas limitações ou das demandas de maior participação das instâncias subnacionais nas deliberações político-administrativas. Suas normas e suas trajetórias têm estabelecido regras e dinâmicas de relações entre os entes federativos na educação que vão formando um legado a marcar as cruciais decisões de regulamentação do Sistema Nacional de Educação e da cooperação federativa da educação. 


\section{Para finalizar: as políticas públicas como objetos de estudo}

Na introdução, nos referimos às políticas públicas como objetos de reconstrução analítica por parte do pesquisador. Muller e Surel (2002) argumentam que uma política não é uma categoria analítica e sim um contructo social e um constructo de pesquisa. Como constructo social, as políticas se configuram como ações dos atores políticos, ações de expressão do poder público com dimensões institucionais e políticas, que agregam, portanto, interesses e ideias. Como constructos de pesquisa, as políticas emergem do trabalho de construção da problemática por parte dos pesquisadores. Entendemos que essa ideia de constructo de pesquisa é bastante relevante, uma vez que nos coloca, na qualidade de pesquisadores, numa dupla posição nas análises de políticas públicas. Por um lado, termos presente que os estudos não apreendem ou narram as políticas em si, mas as reconstituem, mais ou menos amplamente, dentro de um quadro teórico e metodológico. Por outro lado, as escolhas quanto à construção do objeto de pesquisa, seu recorte, e aos métodos utilizados delimitam o que e como será reconstruído na trajetória da pesquisa.

Lascoumes e Le Galès (2009) apresentam um modelo de análise para o estudo do que chamam de ação pública, que compreende cinco elementos interligados: atores, representações (referenciais cognitivos e normativos), instituições, processos e resultados. Para eles, no estudo das ações públicas, cada um dos elementos, bem como as interações entre eles, são procedimentos incontornáveis para o analista de políticas. As políticas analisadas neste artigo foram objeto de estudos aprofundados que levaram em conta todos ou quase todos estes elementos, contudo, foram reconstituídas acima de acordo com o recorte planejado para este texto.

Nesse recorte, buscamos, por intermédio da descrição de conteúdos referentes a objetivos e linhas mais gerais e essenciais do funcionamento de cada política, e considerando principalmente sua regras normativas, colocar em evidência e contrastar corresponsabilidades dos governos nacional e subnacionais que, relacionadas, conformam uma das expressões político-institucionais pelas quais as políticas se constituem no movimento de sua (re)criação social.

Dada a organização federativa na educação nacional, e a conjugação de princípios de autonomia e interdependência dos sistemas de ensino, julgamos que o exame das atribuições de cada esfera de governo, bem como a concepção de relações intergovernamentais desenhadas nas políticas, são elementos substanciais a ter em conta nos constructos de pesquisa que buscam analisar políticas públicas educacionais no Brasil. Não são os únicos, conjugam-se a outros, mas compõem a base inicial para que se formulem questões e/ou problemáticas sobre a gênese, as práticas e/ou os resultados de políticas. 


\section{Referências}

BRASIL. Constituição. Constituição da República Federativa do Brasil, de 05 de outubro de 1988 [preceitos sobre a educação, na redação original e com a atualização dada pelas Emendas Constitucionais 14/96, 53/06, 59/09]. Disponível em: <http://www.planalto.gov.br/ccivil 03/Constituicao/Constituicao.htm>. Acesso em: 12 out. 2015.

. Lei $\mathbf{n}^{0}$ 12.695, de 25 de julho de 2012. Dispõe sobre o apoio técnico ou financeiro da União no âmbito do Plano de Ações Articuladas [...]. Disponível em: <http://www.planalto.gov.br/ccivil_03/_Ato2011-2014/2012/Lei/L12695.htm>. Acesso em: 13 set. 2013.

Lei $n^{0}$ 11.494, de 20 de junho de 2007. Regulamenta o Fundeb, de que trata o artigo 60 do Ato das Disposições Constitucionais Transitórias [...]. Disponível em

<http://www.planalto.gov.br/ccivil 03/ ato2007-010/2007/Lei/L11494.htm\#art17>. Acesso em 02.08.2014.

. Lei no 10.880, de 9 de junho de 2004. Institui o Programa Nacional de Apoio ao Transporte do Escolar - PNATE e o Programa de Apoio aos Sistemas de Ensino para Atendimento à Educação de Jovens e Adultos, dispõe sobre o repasse de recursos financeiros do Programa Brasil Alfabetizado [...] Disponível em: $<$ http://www.planalto.gov.br/ccivil_03/_ato2004-2006/2004/lei/110.880.htm>. Acesso em: 28 set. 2013.

. Lei no. 9.394, de 20 de dezembro de 1996. Estabelece as Diretrizes e Bases da Educação Nacional. Disponível em: <http://www.planalto.gov.br/ccivil 03/Leis/ L9394.htm>. Acesso em 03. Jun. 2015.

. Decreto $\mathbf{n}^{0}$ 7.083, de 27 de janeiro de 2010. Dispõe sobre o Programa Mais Educação. Disponível em: < http://www.planalto.gov.br/ccivil 03/_ato2007-2010/2010/ decreto/d7083.htm>. Acesso em: 04 jan. 2015.

. Decreto $n^{0}$ 6.094, de 24 de abril de 2007. Dispõe sobre a implementação do Plano de Metas Compromisso Todos pela Educação, pela União Federal, em regime de colaboração com Municípios, Distrito Federal e Estados [...]. Disponível em: <http://www.planalto.gov.br/ccivil_03/ ato2007-2010/2007/decreto/d6094.htm>. Acesso em: 10 jun. 2013.

. Portaria Interministerial $n^{\circ} 17$, de 24 de abril de 2007. Institui o Programa Mais Educação, que visa fomentar a educação integral de crianças, adolescentes e jovens, por meio do apoio a atividades sócio-educativas no contraturno escolar. Diário Oficial da União. Brasília, DF, n. 80, 26 abr. 2007, seção 1, p. 5-6.

- Ministério da Educação. Fundo Nacional de Desenvolvimento da Educação. Resolução CD/FNDE n ${ }^{\circ}$ 18, de 22 de abril de 2004. Estabelece os critérios e as formas de transferência de recursos financeiros ao Programa Nacional de Apoio ao 
Transporte do Escolar. Disponível em: $<$ https://www.fnde.gov.br/fndelegis/action/Ur1PublicasAction.php?acao=abrirAtoPublico\&sgl tipo=RES\&num ato $=00000018 \&-$ seq ato $=000 \& v l r$ ano $=2004 \&$ sgl_orgao $=C D / F N D E>$. Acesso em: 12 jun. 2013.

.Ministério da Educação. Fundo Nacional de Desenvolvimento da Educação. Resolução CD/FNDE $\mathbf{n}^{\mathbf{0}}$ 12, de 17 de março de 2011. Estabelece os critérios e as formas de transferência de recursos financeiros do Programa Nacional de Apoio ao Transporte do Escolar (PNATE). Disponível em: $<$ https://www.fnde.gov.br/fndelegis/action/UrlPublicasAction.php?acao=abrirAtoPublico\&sgl tipo=RES\&num $\underline{\text { ato }}=00000012 \&$ seq_ato $=000 \& v 1 r$ ano $=2011 \&$ sgl_orgao $=C D / F N D E / M E C>$. Acesso em: 22 jun. 2013.

. Ministério da Educação. Fundo Nacional de Desenvolvimento da Educação. Resolução CD/FNDE $\mathbf{n}^{0}$ 29, de 20 de junho de 2007. Estabelece os critérios, os parâmetros e os procedimentos para a operacionalização da assistência financeira suplementar a projetos educacionais, no âmbito do Compromisso Todos pela Educação, no exercício de 2007. Disponível em: $<$ https://www.fnde.gov.br/fndelegis/action/UrlPublicasAction.php?acao=abrirAtoPublico\&sgl tipo=RES\&num $\underline{\text { ato }}=00000012 \&$ seq_ato $=000 \& v 1 r \_$ano $=2011 \& s g 1$ orgao $=C D / F N D E / M E C>$. Acesso em: 06. Set. 2012.

FARENZENA, Nalú. Capacidades de financiamento da educação básica no Fundeb: uma costura. In: FERNANDES, Maria Dilnéia. GOUVEIA, Andréa Barbosa; PINTO, José Marcelino de Rezende. Financiamento da educação no Brasil. Os desafios de gastar 10\% do PIB em dez anos. Campo Grande: Editora Oeste, 2015, p. 201-227.

FARENZENA, Nalú et all. Relações intergovernamentais em políticas da educação básica brasileira. In: BOLZAN, Doris Pires Vargas (Org.). VI Encontro Internacional de Investigadores de Políticas Educativas [Anais]. Santa Maria, 2014. Disponível em: <http://seer.ufrgs.br/index.php/Poled/article/view/58190/34814>. Acesso em: 15 de setembro de 2015.

LASCOUMES, Pierre; LE GALÈS, Patrick. Sociologie de l'action publique. Paris: Armand Colin, 2009.

MOSNA, Rosa Maria Pinheiro. Avaliação da política pública "Programa Mais Educação" em escolas de ensino fundamental da rede estadual de ensino do Rio Grande do Sul. Porto Alegre: UFRGS, 2014. 249 f. Tese (Doutorado em Educação) - Programa de Pós Graduação em Educação, Faculdade de Educação, Universidade Federal do Rio Grande do Sul, Porto Alegre, 2014.

MULLER, Pierre; SUREL, Ives. Análise das políticas públicas. Tradução de Agemir Bavaresco e Alceu Ferraro. Pelotas: EDUCAT, 2002.

MULLER, Pierre. Les politiques publiques. Paris: PUF, 2006. 
PERGHER, Calinca Jordânia. Política de transporte escolar rural no Rio Grande do Sul: configuração de competências e de relações (inter)governamentais na oferta e no financiamento. Porto Alegre: UFRGS, 2014. 237 f. Tese (Doutorado em Educação) - Programa de Pós Graduação em Educação, Faculdade de Educação, Universidade Federal do Rio Grande do Sul, Porto Alegre, 2014.

SCHUCH, Cleusa Conceição Terre. A implementação do Plano de Metas Compromisso Todos pela Educação em um município do Rio Grande do Sul: um olhar sobre a efetividade institucional da Secretaria Municipal de Educação. Porto Alegre: UFRGS, 2014. 217 f. Tese (Doutorado em Educação) - Programa de Pós Graduação em Educação, Faculdade de Educação, Universidade Federal do Rio Grande do Sul, Porto Alegre, 2014.

SOUZA, Celina. Governos e sociedades locais em contextos de desigualdades e descentralização. Ciência \& Saúde Coletiva, v. 7, n. 3, 2002, p. 431-442.

Recebido em: 29/09/2015

Aprovado em: 30/10/2015 